\title{
IMPROVING STUDENTS' ACHIEVEMENT IN WRITING RECOUNT TEXT THROUGH FOCUS GROUP DISCUSSION ( FGD )
}

\author{
*Wenny Sasmita \\ **Busmin Gurning
}

This study deals with the improvement of students' writing achievement through focus group discussion method. The objective of this study is to find out whether students' writing achievement will be improved through focus group discussion method. This study was conducted by using classroom action research. The subject of this research was class VIII-4 SMPN. 2 Tanjung Pura. The number of the students was 36 students which consist of 18 male students and 18 female students. The research was conducted in two cycles. Each cycle consisted three meetings. The instrument for collecting the data were quantitative data (writing test ) and qualitative data ( observation sheet, interview and field note). Based on the analysis, students' achievement kept improving in every test.

Key Words : Writing, Recount, Focus Group Discussion.

\footnotetext{
* A graduate of English Language and Literature Department of UNIMED
}

** A lecturer of English Language and Literature Department of UNIMED 


\section{INTRODUCTION}

\section{Background of the Study}

Language is considered to be a system of communicating with other people using sounds, symbols, and words in expressing a meaning, idea, or thought. Language has an important thing in human activity. Everybody needs language to interact with other people. Without language, people cannot convey feeling, thought, intention, or information to other both in written and spoken form. Nowadays, English has become international language which is used by many people in the world both in written and spoken form. English helps people to communicate with other people from different culture background. In Indonesia, English has been taught since the kindergarten level up to the university, but in fact, there are many people who cannot comprehend English well. Therefore, to know English well, people must master four basic skills in mastering English, namely listening, speaking, reading and writing.

This study would be focused in writing skills. Writing is one of the language skills that should be acquired in learning a language. Writing also means a process of communication that conveys ideas and opinion in a written form which suggests that the writer and readers should have similar understanding of what is written. The writing process is intended to provide a step by step model for writing so that the finished piece is the best it can be ( Carol Ann Tomlinson, $2005: 181)$.

The writer choose the topic because based on the writer's interview and observation on Teaching Practice Program ( PPL ), most of the students got bored and lost their interest in writing, especially writing recount. They told that writing recount was very difficult for them to be mastered. Students also have limited vocabulary. So that they find it difficult to write well. And also why the students told that writing recount was very difficult, because the students can not know about generic structure and language feature in writing recount. So that, the students do not understand to arranged the simple text.

After the writer observed the students in several meetings, the writer found some factors that showed why this condition happened. The students did not have 
a good motivation to write because the topic was not interesting. When they have limited vocabulary, it is impossible for them to write recount. Other factors like, uninteresting method and teaching process. The students felt that the teaching and learning process was monotonous and uninteresting. Now, in this study, researcher will be focused in score of the students. Because the researcher want to improve the score to the students.

The method that the teacher used in teaching writing was too complex and monotonous. The teacher just explains without asking the students what they do not know. Students need an easy way to make them able to understand the explanation quickly. If the method of the teacher monotonous and uninteresting, the students will be lazy to study the subject.

If the conditions happen, it means that the teaching and learning process uninteresting and be less effective. To change it, teacher needs a suitable method, a technique, or a strategy. The purpose of using them is to solve the problem and to increase the students' achievement in writing skill.

Focus group discussion method the teacher can help students to improve students' achievement in writing particularly writing recount in order that the students can write recount well.

\section{Research Question}

From the explanation above, the writer wants to conduct the research to see how the Focus Group discussion can improve students' achievement in writing, especially writing recount of VIII year of SMP Negeri 2 Tanjung Pura.

\section{Conceptual Framework}

\section{Students' Achievement in Writing Recount}

According to Keith Johnson (2001 : 292 ) says that achievement is concerned with how well a learner has done in relation to particular course or programmer. They usually come at the end of programmers, and are deliberately based on the content covered in it. 
Achievement is useful to the teacher as well as the learners, they indicate how well teaching has succeeded, and where improvements need to be made. Beside that for the students' achievement in writing recount, teacher must know the weakness of the students in writing recount especially. Moreover teacher will give the explains how to write about writing recount. And what is the generic and language feature in writing recount. So that the students know about writing recount and get high score. And teacher can improve students' achievement in writing recount.

Based on the explanation, it is concluded that students' achievement is a success in reaching particular goal by effort, skill, and performance.

\section{Writing Recount}

According Knapp, P. \& Watkins ( 1994 ) says that recount is to list and describe past experiences by retelling events in the order in which they happened (chronological order). Recounts is written to retell events with the purpose of either informing or entertaining their audience (or both).

Recount is one of the text type which has a function to retell or inform an event or activity in the past. Recount almost has the same with narrative because both recount and narrative have a function to tell the activity or event in the past. The different is recount tells the activity or event just to give the information to the readers, but narrative tells the activity or event not only to give information, but also to give a moral lesson by presenting a problematic experience and then will be ended by a problem solving.

In writing recount, there is a generic structure and language feature. The generic structure of recount, is it orientation, event and orientation. The language feature of recount is use past tense, temporal sequence, using action verb and using linking verb.

Based on the above explanation, it can be concluding that recount is a text which retells events or experiences in the past. Its purpose is either to inform or to entertain the audience. There is no complication among the participants and that differentiates from narrative. 
- Generic Structure of Recount

Generic structure or rhetorical structure is a package of events in a text. This generic structure will explain how the stages move through to attain the purpose. Every genre has its generic structure, so do the recount. The generic structure of recount are :

Orientation : Introducing the participant, place, and time. ( when, where, who, etc )

Events : Describing series of event that happened in the past ( what happened).

Reorientation $\quad$ : Closure of the events. It is optional. Stating personal comment of the writer to the story

- Language Feature of Recount

Language features are about general grammatical pattern to form the information, message, and idea in effective sentences, especially in this case. Language features of recount are :

Introducing participant

: I, we, they, my family, etc.

Using Temporal Sequence

: Then, first, etc.

Using linking verb

: was, were, went, met, etc.

Using action verb

: look, go, see, etc.

Using Simple Past Tense

\section{Assessment of Writing Recount}

The following are the assessment criteria used for assessing the task base on appropriate generic structure and grammatical feature (Knapp \& Watkins, 2005:119):

a. Genre based criteria deal with generic features of the text.

b. Textual criteria deal with the way that the text is held together, the way that the text is held

c. Syntactical language criteria deal with the internal structure of the sentence used. 
Based on the explanation above, this study will use the criteria of assessment in scoring writing recount.

Table 2.1 Criteria of Assessment in Writing Recount

\begin{tabular}{|c|c|}
\hline Assessment & Criteria \\
\hline $\begin{array}{l}\text { Generic Structure } \\
\text { - Orientation } \\
\text { - Event } \\
\text { - Reorientation } \\
\end{array}$ & $\begin{array}{l}\text { - Introducing the participant } \\
\text { ( when, where, who, etc ). } \\
\text { - Explain about some problems } \\
\text { - Closure of the event }\end{array}$ \\
\hline Language Feature & $\begin{array}{l}\text { - Using simple past tense } \\
\text { - Using action verb } \\
\text { - Using temporal sequence } \\
\text { - Using specific participant }\end{array}$ \\
\hline & $\begin{array}{l}\text { - } \text { Language use } \\
\text { - Organization } \\
\text { - Content } \\
\text { - Vocabulary }\end{array}$ \\
\hline
\end{tabular}

Criteria Score :

$\begin{array}{ll}\text { Very Good } & : 25-20 \\ \text { Good } & : 19-15 \\ \text { Poor } & : 14-5 \\ \text { Low } & : 4-1\end{array}$

Focus Group Discussion ( FGD)

According to Krueger (1988) focus group discussion (FGD) is a group discussion of approximately 6 - 12 persons guided by a facilitator, during which group members talk freely and spontaneously about a certain topic.

Focus group discussion is a qualitative method. Its purpose is to obtain indepth information on concepts, perceptions and ideas of a group. Focus group 
discussion aims to be more than a question-answer interaction. The idea is that group members discuss the topic among themselves, with guidance from the facilitator.

Focus group discussion has a goal that is to get input, and also information about a case. On the other hand, focus group discussion is a group discussion not interview or chat.

Implementation of focus group discussion is an iterative process, each focus group discussion builds on the previous one, with a slightly elaborated or better-focused set of themes for discussion. Provided the groups have been well chosen, in terms of composition and number (see below), focus group discussion can be a powerful research tool which provides valuable spontaneous information in a short period of time and at relatively low cost.

According to Currle ( 1993 ) focus group discussion is a group discussion which enables students to do analysis and understanding of a selected topic on the basis of common group characteristics.

The focus group discussion (FGD) is a rapid assessment, semi-structured

data gathering method in which a purposively selected set of participants gather to discuss issues and concerns based on a list of key themes drawn up by the researcher/facilitator (Kumar 1987).

According to ( Kumar 1987 ) There are Step by Step in Teaching through Focus Group Discussion:

Before the focus group discussion begins, the facilitator should obtain the background information of participants such as their age, crops grown, farm size, and other pertinent information. The type of information to collect depends on the FGD topic. Once this is done, this sequence of steps is carried out:

1. The facilitator divided into some group.

2. Each group consists of 6-12 students.

3. The facilitator asks the participant to introduce themselves. 
4. After a brief introduction, the purpose and scope of the discussion are explained.

5. Participants are asked to give their names and short background information about themselves.

6. The discussion is structured around the key themes using the probe questions prepared in advance.

7. During the discussion, all participants are given the opportunity to participate.

8. Use a variety of moderating tactics to facilitate the group. Among these tactics that the moderator can use include:

- Stimulate the participants to talk to each other, not necessarily to the moderator.

- Encourage shy participants to speak.

- Discourage dominant participants through verbal and nonverbal cues.

The following may be used when the situation permits:

- Call on other participants

- Politely intervene by saying, "Maybe we can discuss that in another occasion.

- Look in another direction 
- Take advantage of a pause and suggest that the subject can be discussed

detail in another session

Based on the above explanation, it can be conclude that focus group discussion is a process of collecting data and information systematically in particular problem specifically through group discussion.

Writing Recount through Focus Group Discussion (FGD)

Writing is a process of communication that conveys the idea and thoughts to the readers in the written form that is done by the students. The aims of writing recount are to help students to express their ideas and thoughts about events in the past and to help them to write more effectively.

Almost students feel difficult in writing recount because it is very hard for them to express their ideas and thoughts in the form of sentences. Thus, it is very important to choose suitable technique which can make them more enjoyable and more comfortable in the process of writing recount. One of the interesting and enjoyable techniques is focus group discussion.

Focus group discussion is one of good method in writing recount. In learning process, teacher asks the students to choose one title about their experience, and each group give the title to the teacher. And then, each group must be developing about the title, all of the members in group give the idea, suggestion or command.

\section{METHODOLOGY}

\section{Research Design}

This research would be conducted by applying classroom action research. . Classroom action research was applied because it focuses on individual or small 
group professional practice and it was not concerned with making general statement. A classroom action research was conducted because it gave the improvement of students' skill.

According to Eileen Ferrance (2000: 1 ) states that action research is a process in which participant examine their own educational practice systematically and carefully, using the techniques research.

It is based on the following assumptions:

a. Teachers and principals work best on problems they have identified for themselves.

b. Teacher and principals become more effective when encouraged to examine and assess their own work and then consider ways of working differently.

c. Teachers and principals help each other by working collaboratively.

d. Working with colleagues helps teachers and principals in their professional development.

Action research is a collaborative activity among colleagues searching for solution to everyday, real problems experienced in schools, or looking for a ways to improve instruction and increase student achievement. And also, action research is the idea that teachers will begin a cycle of posing questions, gathering data, reflection, and deciding on a course of action.

\section{Subject of the study}

The subject of this study research was the second year students of SMP Negeri 2 Tanjung Pura, on Jl. Pemuda No. 25 Tanjung Pura Langkat. The sample of the research was students in VIII-4 which consist of 36 students.

\section{Instruments of Data Collection}

In this research, the data would be collected by quantitative and qualitative data. In collecting quantitative data, the subjective test was conducted by the 
writer in order to measure students' ability in writing. Teacher was gave the certain topic and students should write in recount text.

The qualitative data was used to describe the situation during teaching process. The qualitative data would be collected by using observation sheet, field note and check list.

Observation sheet was Focused on the situation of teaching learning process, students' activities and behaviors, and students' ability by using focus group discussion method. For the more, to know daily activity of the students, the researcher using field note to transcribed notes or the written account derived from data collected during observation and interviews. And also the researcher using check list to the list. Which is the purpose is to know the activity all of the students.

Based on the explanation above, it can be conclude that the quantitative data was used a test and qualitative data would be collected by using observation sheet, field note and check list.

\section{The Procedure of the Research}

Before the procedures of data collection would begin, the writer would administer the test to identify the basic knowledge of students about writing recount. The procedures of data collection of the study would be conducted by making two cycles. Each cycle would be conducted in three meetings. Each cycle also consist of four steps namely planning, acting, observing, and reflecting. There was pre-test before conduct the cycle $\mathrm{I}$ in order to get the background situation of the teaching learning in the class and the information of students' knowledge in writing recount text. At the end of teaching learning process in each cycle, the writer was also conduct a test to see the improving students' achievement in writing recount text. Cycle II would be done if there is a need to do it. The writer would decide whether it would be done or not based on the reflection in cycle I. if there was no improvement or significant improvement of students' achievement in writing recount text in the cycle I, the writer would be continue to cycle II. 
The model cycle of Classroom Action Research could be drawn as follows:

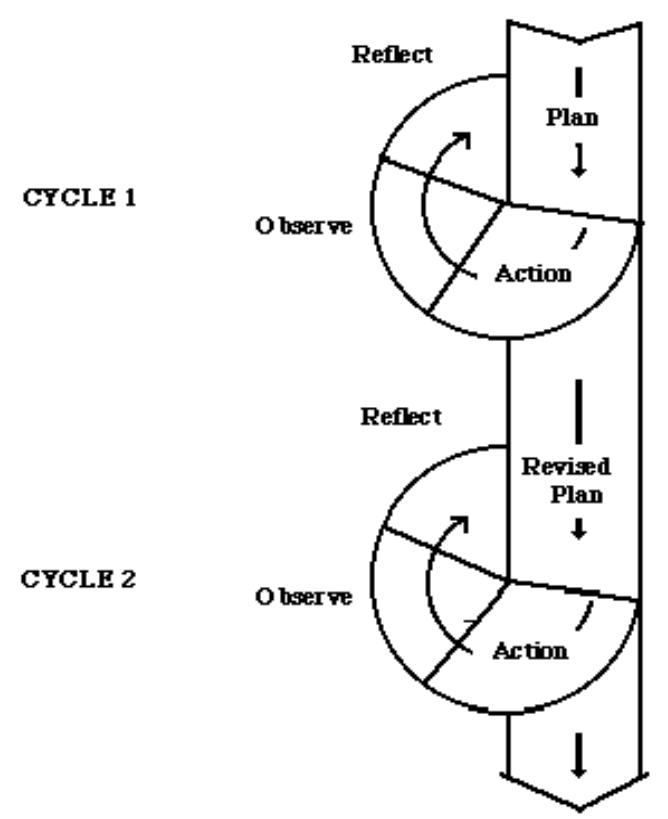

Figure 2.1 Action Research model based on Kemmis and McTaggart (1988) in Burn (2010:9)

\section{Technique of Data Analysis}

The technique of data analysis from this study used quantitative and qualitative data.

The quantitative data is found by analyzing the tests result of the students does with means and the qualitative data is found by describing the situation during in teaching and learning process. The qualitative data is analysis carried out on the activities designed in the classroom, which recorded in observation sheet, filed note and checklist.

\section{RESULTS AND DISCUSSION}

\section{Data}


The writer got the data of students' score in cycle I and cycle II after having done the test related to writing recount. The data in this study were quantitative data ( the test result ) and qualitative data ( interview sheet, observation sheet, and field note ). The first cycle was conducted in three meetings including orientation test and the second cycle was conducted in three meetings. So, there were six meetings in this research.

The research was conducted in second year class of SMPN.2 Tanjung Pura. The subject of this research was taken only from one class which consisted of 36 students.

\section{Data Analysis}

There were six meetings conducted within two cycles in this research. The first test is orientation test which is conducted without focus group discussion. Furthermore for second test and third test was applied through focus group discussion. The qualitative data is used to see the activity of the student and to see the influence of focus group discussion in increasing students' ability in writing. The data were taken by writing about recount text through focus group discussion. The class would be divided into group which is consisted of six students. The result of the students' writing scores can be seen in the following table :

Table 4.1 Students' Score of Orientation Test, Test Cycle I and Test Cycle II

During Six Meetings

\begin{tabular}{|c|c|c|c|c|}
\hline NO & Initial Name & Orientation Test & Cycle I & Cycle II \\
\hline $\mathbf{1}$ & AM & 60 & 75 & 80 \\
\hline $\mathbf{2}$ & AS & 60 & 80 & 85 \\
\hline $\mathbf{3}$ & AH & 60 & 65 & 75 \\
\hline $\mathbf{4}$ & DS & 40 & 70 & 85 \\
\hline $\mathbf{5}$ & DAU & 60 & 75 & 80 \\
\hline $\mathbf{6}$ & DWK & 80 & 90 & 95 \\
\hline $\mathbf{7}$ & ER & 60 & 60 & 75 \\
\hline $\mathbf{8}$ & EH & 80 & 80 & 85 \\
\hline $\mathbf{9}$ & EI & 60 & 65 & 70 \\
\hline $\mathbf{1 0}$ & HAW & 40 & 80 & 85 \\
\hline $\mathbf{1 1}$ & ITW & 80 & 80 & 85 \\
\hline $\mathbf{1 2}$ & IFD & 80 & 80 & 85 \\
\hline $\mathbf{1 3}$ & IS & 80 & 80 & 85 \\
\hline $\mathbf{1 4}$ & LS & 40 & 65 & 70 \\
\hline $\mathbf{1 5}$ & MA & 80 & 80 & 85 \\
\hline
\end{tabular}




\begin{tabular}{|c|c|c|c|c|}
\hline $\mathbf{1 6}$ & MR & 20 & 70 & 75 \\
\hline $\mathbf{1 7}$ & MS & 20 & 68 & 75 \\
\hline $\mathbf{1 8}$ & MN & 20 & 75 & 80 \\
\hline $\mathbf{1 9}$ & MS & 60 & 60 & 70 \\
\hline $\mathbf{2 0}$ & M & 20 & 65 & 70 \\
\hline $\mathbf{2 1}$ & NA & 60 & 80 & 90 \\
\hline $\mathbf{2 2}$ & NS & 80 & 80 & 85 \\
\hline $\mathbf{2 3}$ & N & 60 & 85 & 85 \\
\hline $\mathbf{2 4}$ & OAR & 40 & 70 & 75 \\
\hline $\mathbf{2 5}$ & PHL & 80 & 90 & 95 \\
\hline $\mathbf{2 6}$ & PH & 80 & 80 & 85 \\
\hline $\mathbf{2 7}$ & PR & 40 & 62 & 65 \\
\hline $\mathbf{2 8}$ & PL & 80 & 80 & 95 \\
\hline $\mathbf{2 9}$ & RP & 60 & 70 & 75 \\
\hline $\mathbf{3 0}$ & SS & 40 & 70 & 75 \\
\hline $\mathbf{3 1}$ & SZ & 80 & 80 & 95 \\
\hline $\mathbf{3 2}$ & SIN & 80 & 90 & 90 \\
\hline $\mathbf{3 3}$ & SAR & 80 & 90 & 90 \\
\hline $\mathbf{3 4}$ & TA & 80 & 80 & 90 \\
\hline $\mathbf{3 5}$ & WST & 80 & 80 & 85 \\
\hline $\mathbf{3 6}$ & YL & 20 & 65 & 75 \\
\hline & Total & 2140 & 2715 & 2935 \\
\hline & Mean & 59.44 & 75.41 & 81.52 \\
\hline
\end{tabular}

From the table above, it can be seen that the students' score kept improvement. It because focus group discussion can improve students' achievement in writing recount. The teacher explain about focus group discussion method, And then teacher divided into some group, each group consist 6 students. Each group teacher takes the students which high competence, medium competence, and low competence. So that the students can share with their friend about the lesson.

In the orientation test, there was not any treatment given to the students in order to measure the first knowledge in writing test. Some of the students got score above 70. The others students got low score because method used previously is conventional method which can not give opportunity to student to write. Teacher just explain and always gave the task with the students without asks what is did not know with the students. Many factors the students feel difficult to write, like limited vocabulary, can not arrange the word and did not 
know the material, etc. in contrast, based on the interview sheet the student got the highest score because she already got the English course outside the school, and the other reason was that student was also active in the class. But for the others, based on the interview, they said that English was difficult and boring and not interesting. The grammatical structure of English was very complicated and difficult to understand. So based on this reason, the writer should have motivate the students so that they would be brave enough to write well.

In cycle I, the mean of the students' score was about 75.41 and the percentage of the students who got point up to 70 was $41.66 \%$. The improvement occurred because focus group discussion method was applied and most the student must be active in the class, although there are some students who have low activity or medium activity, the score got is not relevant.

In group II for irrelevant score got by SIN, she got score 90, she was very active in the class. She was understood what the teacher explain. For EI he got low score. He not has motivated to learn.

In group III for irrelevant score got by SAR, he got score 90, based on the observation he was got English course outside the school, so that he has more knowledge from his friends.

In group IV, the score in this group was in medium level. Part of them already passed the KKM but some were not. The researcher categorized this group as the passive one. They did not give the good respond to the lesson, they were not spirit enough. From the field note, it could be shown this group not focus to learn. They were just sit but they were not share about learn with their group.

In group $\mathrm{V}$, there were three students got low score, namely DAU, ER, MR. Based on the interview, DAU, ER, MR said that they were lack vocabulary so that they were so difficult to write. And then they were still confused to arrange the word into the sentence.

Based on the filed note, for group VI, this group belong to one of the not active group. Most of the students got low score in students' activity. The weakness of this group, they don't want to listen when the teacher explain in front of the class. And then they won't ask the teacher what they don't understand. 
Based on the field notes and interview sheet, the students still confused and bored in teaching learning process. Because the students did not know about recount text with well. Beside that the students still confused about generic structure and language feature recount text. The writer must be active to teach the students so that the students have good motivation to write recount well. And their score must be pass the KKM 70. So, the writer make cycle II to them, to know the improvement of the students. Whether it would increase or decrease. Another reason was some students still not active in the class when the writer gave some question. And the others were still confused about focus group discussion method. Based on those reason the writer decided to make cycle II.

After giving the cycle two, the researcher got the result that the students already in good score, they are in medium and high activity. Nobody as in low activity. Every students enjoy learn through focus group discussion. Because every students can share their opinion in their group.

Teacher gave one topic about vacation, so the teacher asks the students to made in simple text into group. Each group should be different of the title. Most of the students so enjoy and interested, each students gave the opinion and suggestion about the task.

In cycle II the students more active and enthusiasm to learn in their group. Most of the students interested to learn in the class. The teacher also give the explanation more specific, so that the students understand about the material.

In cycle II, the mean of students' score had improved above the standard KKM ( 70 ). In this cycle all the weakness in cycle I had been repaired.

The percentage of students' who got point up 70 as the standard score of students' recount writing competence showed the improvement of students' ability from first meeting until sixth meeting. The percentage could be seen as follow: 
Table 4.3 The Percentage of Students' Recount Writing Competence

\begin{tabular}{|c|c|c|c|}
\hline Test & Meeting & Students Who Got Up to 70 & \multicolumn{2}{|c|}{ Percentage } \\
\hline Orientation & I & 15 & $41.66 \%$ \\
\hline I & III & 27 & $75.00 \%$ \\
\hline II & VI & 36 & $100 \%$ \\
\hline
\end{tabular}

In writing orientation test, there were 15 students who got points up 70 as the standard score for students' recount writing competence. In writing test I for cycle I, there were 27 students who got points up 70. In writing test II for the cycle II, all the students got points up 70. It had proved that $100 \%$ students got the good score in writing recount. It could be concluded that focus group discussion method worked affectively and efficiently in helping students in improving their recount writing.

Besides, we also could be know the improvement of scores from each student. We could be see table below:

The score orientation test still low, the mean of score orientation test was 59.44. teacher not used the method when give the orientation test. In cycle I the mean of score test I was 75.41. The score better the orientation test. Because the teacher have used the method like, focus group discussion.

Based on the field note, in cycle II the teacher feel enjoy to teach in the class. Because most of the students very enthusiasm to face the material from the teacher. The teacher give explanation more specific through focus group discussion and the students focus to listen what the teacher said. So the score in cycle II improved, the mean in test II in cycle II was 81.52. all of the students got the KKM up to 70. So focus group discussion improved the students' achievement in writing.

Based on data analysis, it could be drawn that all students got improvement on their score. Some of students got high improvement and the others got medium and low improvement.

\section{Research findings}


Based on the analysis, it was found that focus group discussion was able to improve the students' achievement in writing. The students' achievement was improved significantly as showed in the orientation test was 59. 44. For cycle I 75.41, and cycle II 81.52. The obtained high score was based on the activities designed to make the teaching process more excited, active, enthusiasm to follow the teaching learning process through focus group discussion method. Based on the theory, the activity of the students can influence their score. In fact, not all the active students could got the high score and it was already proved by the analysis data.

\section{Discussion}

Focus group discussion one of the method that can invite the students to be active, good motivation and do high activity. Focus group discussion the students can share with their friend about their experience, and one of the students can ask with member of their group, what the title about, and how to write this paragraph act.

Focus group discussion is very important to be applied to increase students' achievement in writing recount because writing recount is a writing which retells events or experiences in the past. Thus, students' can retell their friends or the other groups about their bad or good experiences in the past easily.

By using focus group discussion in writing recount, the students are hoped to be able to write recount easily. Focus group discussion method is hoped to be able to reduce boredom of the students and increase their motivation in writing recount because it can make class more enjoyable and relaxed.

To improve students' achievement, the researcher divided the students in to some group. Each group consists of 6 students. The researcher give the explanation about their subject especially in writing recount. And than the researcher give one example about recount. The students' were asked by the researcher to express their idea and elaborate their brain based on their knowledge and experience. In this case, every member should focus on their friends' opinion because they had to say the next part based on their knowledge and experience too. 
Many students got bored and lazy when the teaching learning process. Because they are said English study it so bored and difficult. But the researcher invite the students to know about focus group discussion method. So the students have the motivation and want to know how about focus group discussion in learning process.

Finally, the lazy students have a motivation to learn, and than they have previous learning which low score, in this moment the students that can know to write especially writing recount. And all of the students got high score in teaching learning process through focus group discussion

It could be concluded that focus group discussion method are :

a. Generally, focus group discussion method improve students achievement in writing recount.

b. Focus group discussion ( FGD ) could to add the good motivation to learn.

c. The students' more active learn by using focus group discussion, because they could share with their friend about their experience.

d. They were active and enthusiastically in expressing their ideas when they were writing recount through focus group discussion.

\section{CONCLUSION AND SUGGESTION}

\section{Conclusions}

Based on the result of the study, the conclusions are drawn as follows:

a. The students felt more enjoy and interested in learning writing through focus group discussion method. It is showed by their enthusiasm and their activity in writing in two cycles in their respond while they were asked about the material.

b. Therefore, focus group discussion improved students' achievement in writing recount text.

\section{Suggestions}


Based on the result of this study, the use of focus group discussion method could improve the students achievement in writing. The following suggestion are offered:

a. For the writer : the writer develops and enriches the knowledge in education and language.

b. For the teacher : it's better by using focus group discussion method in writing recount in teaching learning process, because it's proven that this method improved the students' achievement in writing recount easily and creatively.

c. For the students : students improve their writing ability, so that can write well.

d. For others: can give them some data, sources through focus group discussion method in writing. 


\section{REFERENCES}

Brown, H.D. 2004. Language Assessment: Principles and Classroom Practices. New York: Pearson Education.

Burns, Anne. 2010. Doing action research in English Language Teaching. New York: Rutledge.

Carol, A.T. 2001. Curriculum Design for writing Instruction: California.

Ferrance, E. 2000. Action Research. New York: Brown University.

Freebody, P. 2004. Qualitative research in education. California: British library.

Glass, K.T 2005. Curriculum Design for Writing Instruction. Creating Standards - based Lesson Plans and Rubrics / Kathy Tuchman Glass: foreword by Carol Ann Tomlinson.

Harmer, J. 2004. How to Teach Writing. England: Longman.

Heaten, J.B. 1984. Writing English Language Test. Longman handbooks for Language Teachers general Editors. Donn Byrne: England.

Johnson, K. 2001. An Introduction Foreign Language Learning and Teaching. New York: Pearson Education.

Knapp, P.M.Watkins. 2005. Genre Text and Grammar. Sidney: University of New South Wales. 
Nunan, D. 1999. Second Language Teaching \& Learning. Heinle \& Heinle Publishers. An International Thomson Publishing Company: Boston.

Definition of focus group discussion ( FGD ) research Google http://www . Bincang Media.com. Focus group discussion. Accessed on $28^{\text {th }}$ march 2011

http://www. Sikompeduli.blogspot.com. focus group discussion. Accessed on $15^{\text {th }}$ February 2012

http://www. Writing recount.com. Accessed on 21 October 2011 